\title{
A Study of Monetary Hierarchy Risks of Asia
}

\author{
Tao Ma ${ }^{1, \mathrm{a}}$, Wenli Ding ${ }^{2, \mathrm{~b}}$, Ming $\mathrm{Li}^{3, \mathrm{c}}$ \\ ${ }^{1}$ The Institute of Applied Mathematics, Qujing Normal University, Qujing, China \\ ${ }^{2}$ School of Economics and Management, Yunnan Normal University, Kunming, China \\ ${ }^{3}$ Pan-Asia Business School, Yunnan Normal University, Kunming, China \\ a2977253061@qq.com, bDingwl@163.com, ${ }^{\mathrm{c}} 1194789807 @$ qq.com

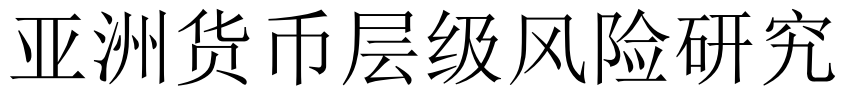 \\ 马涛 $1, \mathrm{a}$, 丁文丽 $2, \mathrm{~b}$, 李明 $3, \mathrm{c}$ \\ ${ }^{1}$ 曲靖师范学院应用数学研究所, 曲靖 655011 , 中国 \\ 2 云南师范大学经济与管理学院, 昆明 650500, 中国 \\ 3 云南师范大学泛亚商学院, 昆明 650000 , 中国 \\ a2977253061@qq.com, bingwl@163.com, ${ }^{\mathrm{c}} 1194789807 @ q q . c o m$
}

\begin{abstract}
A comprehensive introduction of different currencies in different regions within Asia are given. Based on such analysis the paper tries to divide Asian currencies into 5 hierarchies. At present, the Japanese Yen is the Top 1 currency in Asia, Chinese Renminbi stands on the second hierarchy, Hongkong Dollar, Thai Baht, Singapore Dollar, Malaysian Ringgit and South-Korean Won belongs to the third hierarchy, most other currencies in Asia, such and Indian Rupee and Vietnamese Dong etc., belongs to the fourth hierarchy, the most special currency status in Asia is Timor-Leste, she only issue fractional currency, thus it was divided into the fifth hierarchy. The hierarchy will be stable for some time. There are two main risks for the hierarchy, the first is that Japanese Yen is competing direct with RMB which might block the speed of RMB internationalization, the second is that the regional monetary cooperation might have some shocks to Asian monetary hierarchy.
\end{abstract}

Keywords-the geography of money, Asian currency, currency hierarchy, Renminbi Internationalization

摘要一本文大致介绍了当前亚洲不同区域的货币概况，通 过分析进一步把当前亚洲货币划分为五大层级, 第一层级为 日元，第二层级是人民币，第三层级是港币、新加坡元、泰 铢、马来西亚林吉特以及韩元, 第四层级是大部分其他国家 货币, 譬如印度卢比和越南盾等, 鉴于东帝汶主币采用美 元, 自身只发行辅币, 这种货币形态在本文中被划分为第五 层级。当前亚洲货币层级将稳定一段时间, 货币层级风险主 要有两个，其一是日元直接与人民币竞争，可能阻碍人民币 国际化的步伐，其二是区域货币合作可能对当前亚洲货币层 级带来冲击。

关键词一货币地理，亚洲货币，货币层级，人民币国际化

$$
\text { I. 引言 }
$$

货币地理理论认为: 从最根本上来讲, “货币地 理” 是指货币关系的空间组织——即货币区域是如何形 成和治理的（Cohen,1998,P8）。

提到货币地理的问题，有必要追溯到 “威斯特伐利 亚” 模式。1648 年, 在德国西北部的威斯特伐利亚地区 签订的《威斯特伐利亚和平条约》 ( Peace of Westphalia）中承认每个主权国家在其领土范围内享有
主权，真正的货币主权范围与其领土范围一致。威斯特 伐利亚体系将主权国家概念引入国际关系, 并一直影响 至今。从货币地理的视角来看, 威斯特伐利亚模式认为 领土货币的作用范围完全与主权国家的领土范围相同， 这种货币作用空间与发行国主权范围完全相同的理解模 式, 即是威斯特伐利亚模式。威斯特伐利亚模式具有特 定的时空背景, 但随着社会的发展, 现实社会中货币与 国家领土和主权之间的关系远非威斯特伐利亚模式所能 涵盖。亚洲各种货币的作用范围与国家领土和主权之间 的关系也非威斯特伐利亚模式所能涵盖, 具有自己鲜明 的特点：比如我国 “一国多币” 的特殊货币体制; 巴勒 斯坦至今没有自己的货币，同时在使用以色列货币（谢 克尔) 和约旦货币 (第纳尔) ; 东帝汶采用美元作为主 币, 自身只发行辅币等等。当前, 对亚洲货币层级问题 进行探析，会对人民币国际化的国家战略有所助益。

\section{II. 科恩对货币层级的划分}

对于货币层级，科恩给出了他认为的货币金字塔， 共分七个层级。第一, 顶级货币。此种货币在所有跨境 交易中占支配地位, 其受欢迎程度普遍, 并不被特定的 地理区域所限制。自二战以后美元是当今世界唯一的顶 级货币。第二, 贵族货币。此种货币用于各种跨境交易 目的, 但受欢迎程度及使用的普遍性低于顶端货币, 比 如日元。第三, 精英货币。此种货币可用于重要的国际 使用, 但其权重不足, 更多的用于其边境周围。比如英 镑、加拿大元。第四, 平民货币。其国际使用的情况较 为有限, 其货币的独立性可能更多是来自国外对其的认 可。比如新加坡元、韩元、阿拉伯联合酋长国迪拉姆。 第五, 渗透货币。这种货币的权威有效区域通常是在其 国内, 货币替代主要通过市场驱动完成, 虽然仍存在名 义上的货币主权和政府的发行权, 但外国货币至少因为 某些货币目标而排挤本国货币。Cohen 认为，大部分发 展中的经济体的货币都属于渗透货币的范畴。第六, 准 货币。从功能上来看, 这些货币不但在价值储藏功能上 被排挤, 在很大程度上, 其另外两个功能（记账单位、 交换媒介）也被排挤。他认为拉丁美洲地区和前苏联地 区这种货币的情况比较明显。第七, 伪货币。此种货币 处于金字塔的最底端, 这些货币有名无实, 虽有法律地 
位, 但对经济无意义, 因此称为伪货币。比如利比亚 元。事实上有些伪货币已经完成了被其他货币替代的过 程, 比如巴拿马银币（Panamanian balboa）已经被美元 所取代。上述七种货币构成了货币金字塔结构，体现了 货币在竞争过程中的层级关系。

\section{III. 当前亚洲货币概况}

\section{A. 东亚货币概况}

\section{1) 人民币概况}

随着时代的发展，当前，我国稳定的政治局面，世 界第二的经济总量客观上也要求人民币应有与我国大国 地位相匹配的国际地位，鉴于此，国家自 2009 年开始官 方推进人民币国际化，至今为期，人民币在国际货币体 系中扮演者越来越重要的角色，跨境贸易人民币结算、 人民币离岸金融建设、人民币加入 IMF 的货币篮子、人 民币与其他国家的货币互换等诸多领域取得了显著的成 绩，但还应清楚的认识到，就国际支付货币和官方外汇 储备货币的比例而言，人民币与美元、欧元仍有较大差 距，但在亚洲有逐步赶超日元之势。

\section{2) 日元概况}

日本政府在 1871 年（明治维新时期，1868-1912) 开始发行纸币，标志着日元的诞生。日元诞生后的很长 一段时间都在实行金本位制，直至第一次世界大战爆 发。

二战后，日本经济迅速发展，到 20 世纪 70 年代 初, 日本的经济总量跃居世界第二, 日元的国际化也成 了日元走上国际货币舞台的一个象征。日元的国际化大 致经历了三个时期：初期经济总量和贸易总量推动、20 世纪 80 年代日本政府积极推动、 20 世纪 90 年代日本经 济泡沫破裂和亚洲金融危机的爆发让日元国际化受到重 大影响。

日元国际化虽难言成功，然而，日元仍是国际货币 体系中非常重要的一种货币，无论是从国际支付货币排 名、官方外汇储备构成以及 IMF 的货币篮子权重来看, 都稳定排在世界货币的第三或第四的位置。

总之，日元目前在国际货币体系中仍然是一种比较 重要的货币，按照科恩对国际货币等级金字塔的分类， 日元在世界货币等级中的处于金字塔的上部，属于仅次 于美元的贵族货币。在亚洲，日元当前处于货币层级的 顶端位置。

\section{3) 韩元概况}

1953 年 1 月 16 日, 朝鲜货币禁止在韩国流通, 此时 韩元基本实现了货币统一，这一阶段可看成韩元的第一 次改革。

随着韩国国民经济的发展以及交易的需要，到了 20 世纪 70 年代, 韩元的发展变化主要体现在货币面值的变 化之上。1962 年韩国有 8 种面值的货币（500，100， $50,10,5,1$ Won 元, 辅币 50, 10Jeon 钱)，到 1975 年前后，韩国有 9 种面值的货币（10000,5000,1000， $500,100,50 ， 10,5,1 \mathrm{Won}$ ）其中 500 面值及其以上的为纸 币，100 面值及其以下的为硬币。2006 年以后，韩元的 发行与治理主要体现在工艺和防伪之上, 当然，2009 年 韩国再次在时隔 36 年之后发行大面额纸币，面额达
50000 元（Won），虽然自 20 世纪 70 年代以来其纸币 和硬币的设计有所改变, 但总体来说, 20 世纪 70 年代 韩国的货币框架形成，并长期稳定至 21 世纪初期。

4) 朝鲜元概况

二战期间，朝鲜沦为日本的殖民地，并没有本国货 币, 当时国内流通的是受日本严密控制的朝鲜银行发行 的货币，其汇率与日元为 $1: 1$ 的相等关系。二战后的 1948 年 9 月以金日成为元首的朝鲜民主主义人民共和国 在朝鲜半岛北部成立, 解放初期, 朝鲜尚有三种货币同 时流通。为货币统一和创立本国货币的需要，1946 年 1 月北朝鲜银行成立, 成为发行的银行，1947 年 12 月朝 鲜实行第一次货币改革, 发行本国货币, 与旧币的兑换 比价为 $1: 1$ 。

1947 年以来朝鲜政府先后进行了 5 次货币改革。最 后一次是 2009 年, 此次货币改革, 兑换比率为 1:100, 即 100 元旧币兑换 1 元新币, 也就是说通过货币兑换又 一次对原货币进行了百倍的升值。针对此次货币改革, 批评的声音很多。货币升值会导致物价上涨, 虽有助于 治理其国内出现的严重的通货膨胀问题，但却有可能走 向另一端, 即带来通货紧缩的问题, 不利于其国内经济 的发展。另外, 货币的升值意味着老百姓手里持有的财 产大幅缩水, 而朝鲜真正的富有人士或许可以多元化持 有资产与外汇, 而非仅仅持有朝鲜本币, 这一部分人财 产虽有损失，但由于其经济实力雄厚，损失在可承受的 范围之内; 而普通老百姓的的财产在真正意义上大幅缩 水，此次 “货币改革成了剥夺全国人民群众财富的行 为”（胡国洪，2012）, 在世界政治经济领域, 朝鲜长 期高度的计划经济体制, 已经让它在世界范围内显得特 立而独行，在 IMF 等主要国际金融机构检索其相关数据 时往往为空，相对封闭的国民经济管理体制使得其货币 也不大可能在短期内以向世界开放的姿态走出去完成区 域货币合作，更不用说国际货币合作的进程。

\section{5) 蒙古图格里克概况}

1949 年新中国成立之后, 中国陆上疆界长度达 22800 多公里, 与朝鲜、俄罗斯、蒙古、哈萨克斯坦、 吉尔吉斯斯坦、塔吉克斯坦、阿富汗、巴基斯坦、印 度、尼泊尔、不丹、缅甸、老挝、越南共 14 个国家接壤 相邻, 中国大陆海岸线长达约 18000 公里, 与韩国、日 本、菲律宾、文莱、马来西亚、印度尼西亚等 6 国隔海 相望。渤海、黄海、东海和南海是中国大陆濒临的近 海, 沿海分布着海南岛、台湾岛、舟山群岛、崇明岛、 南海诸岛等超过 7500 个岛屿。中国自身的地理大致情况 是西高东低, 地形复杂多样, 以高海拔山地为主。从漫 长的中世纪历史上来看, 总体说来, 虽然中国地理版图 有 “伸缩”，但这种 “伸缩” 它只有 “胖瘦”之分而无 “器质” 裂变, 因此中国地缘政治的基本要素在中国古 今历史上还是一贯的。这一基本要素让我们在理解中国 地缘政治时只用抓住它即可, 而不必直于不同历史阶段 中国历史版图的具体大小与伸缩变化。实际上, 在上下 五千多年的历史中, 像中国这样一直保持地理上的大版 图且自然资源丰富的国家实属罕见。

\section{B. 中亚五国货币概况}

中亚 5 国分别是哈萨克斯坦、乌兹别克斯坦、吉尔 吉斯斯坦、塔吉克斯坦、土库曼斯坦。自 1989 年以来, 
后苏联国家呈现不同的发展轨迹, 按所属大洲, 从地理 上大致可以分为亚洲独联体国家和欧洲独联体国家。

亚洲独联体国家共有 8 个, 面积约 419 万平方千 米。其中哈萨克斯坦以 2724900 平方千米的领土面积在 亚洲的独联体国家中排名第一, 在亚洲第三。作为一个 具有代表性的亚洲独联体中亚大国，哈萨克斯坦于 1991 年 12 月 16 日通过《哈萨克国家独立法》，正式宣布独 立，同年 12 月 21 日加入独联体。1991 年 12 月 26 日， 随着苏联解体，成为真正独立的主权国家。而直到 1993 年 11 月 15 日，哈萨克斯坦中央银行才正式发行本币坚 戈（Tenge），取代俄罗斯卢布成为合法通货。自哈萨 克斯坦和乌兹别克斯坦先后于 1993 年和 1994 年分别决 定发行本国货币起,卢布区宣告解体。在此之前, 哈萨克 斯坦同其他独联体国家一样，因为没有自己国家独立的 中央银行体系，在货币上受制于俄罗斯。而出于利益问 题, 俄罗斯随后因新卢布供应而提出的 “过于苛刻” 的 条件，催化了哈萨克斯坦等独联体国家发行本国货币的 决心，导致了新卢布区的解体。新卢布区给哈萨克斯坦 等独联体国家留下的历史伤疤尚存, 历尽艰辛才建立起 本国的中央银行和发行本国货币。

\section{C. 西亚国家主要货币概况}

西亚 20 国包括: 沙特阿拉伯、科威特、阿拉伯联合 酋长国、卡塔尔、阿曼、巴林、阿塞拜疆、格鲁吉亚、 亚美尼亚、伊朗、伊拉克、土耳其、叙利亚、约旦、以 色列、阿富汗、巴勒斯坦、也门、黎巴嫩、塞浦路斯。

在西亚国家, 海湾地区的货币情况具有一定的代表 性。海湾国家对区域货币有自己的看法和行动, 海湾区 域货币联盟虽已有时日，但尚在步履蹒跚。

地缘、政体和宗教的特殊性, 让沙特阿拉伯、科威 特、阿拉伯联合酋长国、卡塔尔、阿曼和巴林等 6 个国 家早在 1981 年组成海湾合作委员, 并于 2001 年决定在 2010 年 1 月启动货币联盟, 以推动地区经济一体化。在 海湾六国中, 沙特阿拉伯以 2250000 平方千米的领土面 积居亚洲第 4 位, 全境大部分领土位于阿拉伯高原, 沙 漠约占国土面积的 $1 / 2$ 。沙特王国是当今世界上最典型 地实行 “政教合一” 制度的国家, 因此也是海湾六国中 最具典型的代表国。

但 2006 至 2007 年阿曼和阿联酋先后因各自的原因 宣布退出货币联盟，科威特也宣布其货币第纳尔与美元 脱钩, 转而与一篮子货币挂钩。曲折的货币联盟之路, 让原定于 2010 年实施区域货币联盟的决定流产，国际货 币基金组织也曾质疑海湾货币一体化进程。实际上，时 至 2018 年底, 海湾六国的货币一体化问题仍未实现。

其他国家的货币基本处于本国正常发行，在本国地 理范围正常使用。譬如, 西亚独联体三国（阿塞拜疆、 格鲁吉亚、亚美尼亚）的货币问题与中亚 5 个 “斯坦” 国历史背景相同，历经艰辛能够自己发行货币，但直到 前两年仍然受货币贬值、汇率管理等各种问题困扰。

\section{$D$. 南亚主要国家货币概况}

南亚 7 国包括: 印度、巴基斯坦、孟加拉、尼泊 尔、不丹、斯里兰卡、马尔代夫。
从货币的使用人口和货币作用范围的地理面积来 看，印度货币卢比是南亚地区比较重要的货币。

印度虽于 1947 年 8 月 15 日就宣布从殖民地独立出 来, 但印度共和国的正式独立日却是在 1950 年 1 月 26 日。在此期间, 印度的货币卢比也一直由印度的中央银 行一一印度储备银行 (Reserve Bank of India) 发行。在 此之后, 卢比的发行也只有设计和面额上的变化, 以体 现印度的独立。从印度共和国正式成立以来至今, 印度 虽是世界上的地理面积大国之一以及世界第二人口大 国, 但受制于印度本身的经济发展水平, 印度卢比在世 界支付货币排名及国际储备货币排名中可以说是名不见 经传, 远不如泰铢、新加坡元等货币的国际地位。

孟加拉货币达卡、巴基斯坦卢比、尼泊尔卢比和不 丹货币等情况比较相似, 受制于这些国家本身的经济总 量较小和发展比较滞后的影响, 这些货币从发行之初到 现在的主要变化也只是体现在面额和防伪等特征的变化 之上，并非南亚区域内主要的货币问题。

\section{$E$. 东南亚国家货币概况}

东南亚 11 国包括: 泰国、马来西亚、新加坡、印度 尼西亚、菲律宾、文莱、柬埔寨、老挝、缅甸、越南、 东帝汶。 度。

东南亚部分国家的货币在国际范围有一定的知名

从 SWIFT 公布的在 2019 年 6 月国际支付货币的排 名情况来看, 前 20 名国际支付货币当中, 亚洲有 6 种货 币名列其中, 其中东南亚国家共有 3 个名额, 分别是排 名第十的泰铢（THB），排名第 12 的新加坡元 (SGD) 排名第 17 的马来西亚林吉特（MYR）。

而东帝汶则是采用美元作为其主币, 自己只发行与 美元等值的辅币。

其他几种货币基本都是本国发行在本国范围内流通 使用, 这些货币的国际使用极少, 亦非东南亚地区的主 要货币问题。

\section{IV. 当前亚洲货币层级划分}

\section{第一层级：国际化使用较高的货币一一日元}

20 年前, 科恩在对世界货币进行层级划分时, 日元 被划分为仅次于美元的贵族货币。 20 年后的今天, 这一 状况在亚洲并未发生根本性的变化, 目前, 从国际货币 体系来看, 日元虽与美元、欧元等关键货币仍有差距, 但在亚洲仍然是毫无疑问的第一货币。

国际支付货币方面: 2019 年 6 月, 日元占国际支付 货币份额的 $3.73 \%$, 是亚洲国家货币份额占比及排名最 高的货币。

世界官方外汇储备货币方面: 日元是亚洲货币当中 最早被 IMF 列入官方外汇储备货币的币种，2019年第一 季度, 日元以折合 5720.7 亿美元的额度高居全球官方外 汇储备货币的第 3 位, 仅次于美元与欧元, 在亚洲排名 第一。

从上述两大可以量化的指标来看, 日元毫无疑问是 目前亚洲第一层级的货币。 
第二层级：国际化程度蒸蒸日上的货币一一人民币

中国自 2009 年通过跨境贸易人民币结算官方正式推 进人民币国际化的进程。人民币国际化之初，人民币在 国际支付货币方面的排名远在 35 名之外, 在亚洲有好几 种货币的国际支付货币排名都远在人民币之上，10 年人 民币国际化之路, 让人民币在国际化的道路上不断取得 突破。

国际支付货币方面: 2019 年 6 月, 在亚洲范围, 人 民币在国际支付货币的占比为 $1.99 \%$ ，仅次于日元。

世界官方外汇储备方面：人民币已经成为亚洲仅有 的两种被 IMF 明确列入官方外汇储备币种的货币之一， 2019 年 1 季度, 人民币以折合 2128.7 亿美元的额度居全 球官方外汇储备货币的第 5 位，在亚洲排名第二。

按目前这两个指标评测, 人民币当前属亚洲第二层 级的货币。

第三层级: 有一定国际使用但使用范围较为有限的 货币，如：港币、新加坡元、泰铢、马来西亚林吉特以 及韩元

之所以把这几种货币划入亚洲货币的第三层级, 是 因为除日元和人民币以外, 亚洲仅有这几种货币长期居 全球国际支付货币的前 20 位（韩元不在此列），其他货 币无数据可查。

2019 年 6 月明确列入全球国际支付货币前 20 名的货 币之中, 港币排名世界第 8 , 亚洲第 3, 占全球国际支 付货币的 $1.53 \%$; 新加坡元排名世界第 9 , 亚洲第 4, 占 全球国际支付货币的 $1.05 \%$; 泰铢排名世界第 10 , 亚洲 第 5, 占全球支付货币的 $1.01 \%$; 马来西亚林吉特排名 世界第 16 , 亚洲第 6, 占全球支付货币的 $0.40 \%$ 。

另外, 按照科恩 (1998) 对货币层级的划分, 韩元 因当时与新加坡元同被列入 “平民货币” 这一层级, 其 货币的国际使用虽然较少, 但其货币的独立性可能更多 来自于其他国家对其的认可, 因此可归入亚洲货币的第 三层级。

第四层级：名义上具有货币主权和发行权的货币， 但货币的国际使用极少, 比如: 印度卢比、越南盾等, 目前，亚洲大部分国家的货币可归属于此列。

第五层级：主币采用其他国家发行的货币——东帝 汶的货币。

这一层级的货币基本上处于亚洲货币的最后一个层 级, 东南亚的东帝汶是亚洲货币地理中比较独特的一种 形态, 在东帝汶正式独立之前的 2001 年 8 月, 联合国东 帝汶过渡行政当局就决定, 自 2001 年 8 月 20 日开始, 东帝汶所有交易都要使用美元计算, 不得使用其他货
币。东帝汶 2002 年正式宣布独立以来, 通用美元, 东帝 汶自己则发行与美元等值的硬币。

东帝汶所发行的硬币虽与美元等值, 但其主币完全 采用美元, 失去了货币在发行和主权上的独立性, 被划 入亚洲货币的第五层级。

\section{V. 结论与讨论}

通过对亚洲货币脉络的梳理, 最终把当前亚洲货币 分为五个层级。日元属第一层级, 人民币属第二层级, 港币、新加坡元、泰铢等属于第三层级; 印度卢比、越 南盾等大部分其他亚洲国际的货币属第四层级; 而主币 采用美元, 自身只发行辅币的东帝汶被划分为第五层 级。

日元作为当前亚洲第一层级的货币在亚洲范围内直 接与人民币进行竞争, 有可能在一定程度上阻碍人民币 国际化的步伐, 是亚洲范围内人民币国际化竞争性货币 的主要风险因素之一。当然, 从我国近年来 GDP 总量、 进出口贸易总额以及国际储备规模来看, 人民币取代日 元成为亚洲第一层级货币只是时间问题。亚洲货币层级 未来的风险因素可能主要来自于区域货币合作, 譬如东 盟货币金融合作, 海湾地区货币合作等进程的发展状 况，应给予持续关注。

\section{致谢}

本项目受国家自然科学基金课题 “基于多国 CGE 模 型的人民币与东盟国家货币外汇市场福利效应研究” （编号：71363064）资助。

\section{通讯作者}

丁文丽, 云南师范大学经济与管理学院, 昆明 650500, 中国, dingwl@163.com

$$
\text { 参考文献 }
$$

[1] 巴里 ·艾肯格林. “资本全球化:国际货币体系史, ”上海人民出版 社, 2009.193.

[2] 傅雪莹, 陈才, 刘继生, 等. “世界金融地理层级性研究, ”地理科学, 2011, 31(12):1447-1453.

[3] 大卫・兰恩.David Lane. “世界体系中的后苏联国家:欧盟新成员 国、独联体成员国和中国之比较”俄罗斯研究,2010(5):51-73.

[4] Abdullah Alam. "Crisis Transmission: Global Financial Crisis" Journal of Risk Analysis and Crisis Response, vol 2, issue 3, November 2012, 157 - 165 .

[5] Dusan Marcek, Lukas Falat. "Volatility Forecasting in Financial Risk Management with Statistical Models and ARCH-RBF Neural Networks" Journal of Risk Analysis and Crisis Response, vol 4, issue 2, July 2014, $77-95$.

[6] Benjamin J. Cohen. "The Geography of Money" First published 1998 by Cornell University Press.

[7] McKinnon R.I. "Optimum Currency Areas and Key Currencies: Mundell I versus Mundell II” JCMS, 2004(42): 689-715.

[8] Eichengreen B. "The renminbi as an international currency" Journal of Policy Modeling, 2011, 33(5):723-730. 